\title{
Familial Benign Pemphigus
}

National Cancer Institute

\section{Source}

National Cancer Institute. Familial Benign Pemphigus. NCI Thesaurus. Code C82865.

An autosomal dominant disorder characterized by a history of multiple relapses and remissions of pemphigus lesions. 